\title{
The role of palliative care in the management of patients with lung cancer
}

\author{
Irena $\operatorname{Tan}^{*}, 1$ (D) \& Kavitha Ramchandran 1 (D) \\ ${ }^{1}$ Stanford Cancer Center, 875 Blake Wilbur Dr, Palo Alto, CA 94304, USA \\ *Author for correspondence: irenatan@stanford.edu
}

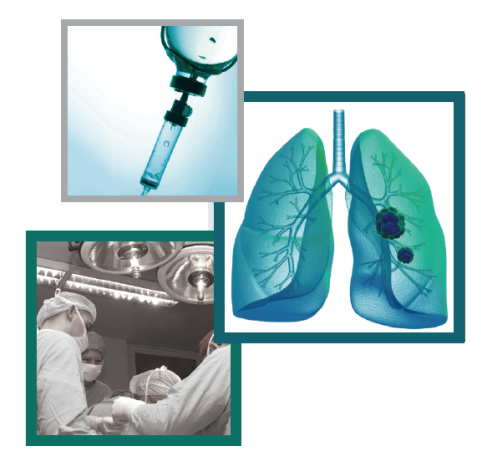

Palliative care (PC) is the care of patients and their families with serious illness and is rapidly becoming an important part of the care of cancer patients. Patients with advanced lung cancer are a highly symptomatic population of patients and clearly experience benefits in quality of life and potentially benefits in overall survival when PC is incorporated early on after diagnosis. However, referrals to PC are still reliant on clinical judgment of patient prognosis and symptom burden. Moving forward, improving the integration of PC and lung cancer care will require more efficient real-time screening of patient symptoms, which may be accomplished through the use of patient-reported outcomes.

First draft submitted: 7 May 2020; Accepted for publication: 13 July 2020; Published online:

29 July 2020

Keywords: end-of-life care $\bullet$ models of care delivery $\bullet$ palliative care $\bullet$ patient-reported outcomes $\bullet$ quality of life $\bullet$ referral criteria • symptom management

Palliative care (PC) is a discipline that has rapidly grown and expanded from the pioneering hospice movement founded by Dame Cecily Saunders in the 1960s. As a field, it is now inextricably linked to the optimal care of patients with severe illnesses, and, in particular, has become an integral part of oncologic care in patients with advanced cancers. It is now widely accepted and recommended that patients with advanced cancers should be referred as early as possible to a PC provider [1]. Increasing evidence has identified the multifaceted ways in which incorporating PC can improve quality of life (QoL) for both patients and their families or caregivers $[2,3]$.

Although the rate of lung and bronchus cancer diagnoses has continued to decline over the past several decades, it is estimated to represent $12.9 \%$ of all new cancer cases in the USA, with approximately 228,150 individuals diagnosed with lung cancer in 2019, and remains the leading cause of cancer-related death in the USA [4]. Lung cancer is associated with a high symptom burden at all stages, with patients at higher stages of cancer more likely to develop severe symptoms, increased pain and increased dyspnea [5]. Given its prevalence and high symptom burden, it should come as no surprise that the effects of PC on lung cancer patients have been the focus of significant research efforts. However, even though the relationship between these two disciplines has helped pave the road for involving PC in oncologic specialties in general, there remain many areas in which the integration and delivery of PC can be improved. In this review, we will describe the current role of PC in lung cancer and how the field can evolve to meet the ever-growing demands for PC in lung cancer patients.

\section{PC: definition}

The WHO (Geneva, Switzerland) has defined PC (PC) as "an approach that improves the quality of life of patients and their families facing the problem associated with life-threatening illness, through the prevention and relief of suffering by means of early identification and impeccable assessment and treatment of pain and other problems, physical, psychosocial and spiritual" [6]. In this definition, PC is provided to patients with serious illness as well as their caregivers, regardless of whether the intent of their treatment is supportive or curative. Even today, the term PC has often been misunderstood as synonymous with hospice care. While hospice care was likely the first formally recognized branch of PC, hospice care is specifically provided to patients who are no longer receiving disease-modifying agents for their disease and whose focus is primarily on comfort. In this review, we will focus on PC as holistic care for patients with serious illness and their families from the point of diagnosis through survivorship and end-of-life. 
Table 1. A selection of relevant trials/studies on the benefits of palliative-care-based interventions in patients with advanced cancer.

\begin{tabular}{|c|c|c|c|c|}
\hline $\begin{array}{l}\text { Study, year } \\
\text { Published }\end{array}$ & Target population & Type of trial & Intervention & Outcomes \\
\hline $\begin{array}{l}\text { Bakitas et al., } \\
2009\end{array}$ & $\begin{array}{l}\text { Newly diagnosed advanced cancer at } \\
\text { single tertiary center and single VAMC }\end{array}$ & $\mathrm{RCT}$ & $\begin{array}{l}\text { APP-led educational session and } \\
\text { monthly telephone follow-up vs } \\
\text { standard of care }\end{array}$ & Improved QoL and mood \\
\hline $\begin{array}{l}\text { Temel et al., } \\
2010\end{array}$ & $\begin{array}{l}\text { Newly diagnosed metastatic NSCLC at a } \\
\text { single tertiary center }\end{array}$ & $\mathrm{RCT}$ & $\begin{array}{l}\text { Early PC (subspecialist referral) vs } \\
\text { standard of care }\end{array}$ & $\begin{array}{l}\text { Improved QoL, improved mood, } \\
\text { decreased aggressive EoL care, } \\
\text { improved overall survival }\end{array}$ \\
\hline $\begin{array}{l}\text { Zimmerman } \\
\text { et al., } 2014\end{array}$ & $\begin{array}{l}\text { Newly diagnosed advanced cancer with } \\
\text { estimated prognosis of } 6-24 \text { months at } \\
\text { single tertiary center }\end{array}$ & Cluster RCT & $\begin{array}{l}\text { Early consultation with follow-up with } \\
\text { PC team vs standard of care }\end{array}$ & $\begin{array}{l}\text { Improved QoL at EoL, improved } \\
\text { satisfaction with care }\end{array}$ \\
\hline $\begin{array}{l}\text { Bakitas et al., } \\
2015\end{array}$ & $\begin{array}{l}\text { Newly diagnosed advanced cancer at } \\
\text { single tertiary center and associated } \\
\text { VAMC and community outreach clinics }\end{array}$ & $\mathrm{RCT}$ & $\begin{array}{l}\text { Initial PC consultation, PC nursing-led } \\
\text { telehealth coaching sessions and } \\
\text { monthly follow-up within } 30-60 \text { days of } \\
\text { diagnosis (early group) vs } 3 \text { months } \\
\text { later (delayed group) }\end{array}$ & $\begin{array}{l}\text { No significant difference in QoL or } \\
\text { resource utilization, but improved } \\
\text { overall survival }\end{array}$ \\
\hline $\begin{array}{l}\text { Dionne-Odom } \\
\text { et al., } 2015\end{array}$ & $\begin{array}{l}\text { Caregivers of patients with advanced } \\
\text { cancer at single tertiary center, } \\
\text { associated VAMC and community } \\
\text { outreach clinics }\end{array}$ & $\mathrm{RCT}$ & $\begin{array}{l}\text { RN-led, } 3 \text { weekly coaching sessions, and } \\
\text { monthly follow-up all done via } \\
\text { telehealth early (at enrollment) vs } \\
3 \text { months later (delayed group) }\end{array}$ & $\begin{array}{l}\text { Improved depression scores at } \\
3 \text { months, improved depression scores } \\
\text { and stress burden at end-of-life }\end{array}$ \\
\hline $\begin{array}{l}\text { Sullivan et al., } \\
2019\end{array}$ & $\begin{array}{l}\text { Stage IIIB/IV lung cancer in the VAMC } \\
\text { system nationwide }\end{array}$ & $\begin{array}{l}\text { Retrospective } \\
\text { cohort study }\end{array}$ & $\begin{array}{l}\text { Compared patients who received at } \\
\text { least one PC encounter vs those who did } \\
\text { not }\end{array}$ & $\begin{array}{l}\text { Improved overall survival if PC } \\
\text { encounter occurred between } 31 \\
\text { and } 365 \text { days after diagnosis, reduced } \\
\text { risk of death in acute care setting }\end{array}$ \\
\hline
\end{tabular}

\section{The evolution of PC in lung cancer}

There now exists a wealth of evidence for the use of PC in lung cancer patients. Likely the most formative trial in PC to date, in 2010, Temel et al. published their seminal paper on early referral to subspecialty PC in patients newly diagnosed with advanced non-small-cell lung cancer [2]. In this trial, patients who were randomized to early subspecialist PC integrated with standard oncologic care experienced a higher QoL, reduced depression scores, received less aggressive end-of-life care and demonstrated a significant if modest improvement in overall survival. This trial sparked intense interest in the benefits of early PC involvement in advanced lung cancer, as well as in all advanced cancers.

Several studies support the QoL benefits and survival outcomes of early PC (Table 1). Project ENABLE, a randomized control trial utilizing 4 weekly educational sessions with advanced practice nurses trained in PC and then monthly telephone follow-ups, demonstrated an improvement in QoL for patients with advanced cancer [7]. In the ENABLE III trial, patients with advanced cancer who received early subspecialty PC consultation with monthly follow-up also demonstrated an improvement of overall survival [8], as well as an improvement in caregiver depression scores and stress burden [3]. Another randomized controlled trial in which medical oncology clinics were randomized to consultation and monthly follow-up by a PC team found that there were significant improvements in end-of-life care and satisfaction with care at their primary end point of 3 months, with significant improvements in additional QoL metrics by 4 months, their secondary end point [9]. Most recently, a retrospective analysis of a large cohort of patients diagnosed with advanced lung cancer, who were seen by a PC provider after their diagnosis, demonstrated an overall association in improved survival as well as reduced likelihood of death in an acute care setting [10]. Interestingly, this association with improved survival was only seen in patients referred within a year but after a month of diagnosis, while patients who were referred within the first month saw an inverse relationship with overall survival. This subset of patients who were referred within a month of diagnosis occurred more in the inpatient setting, suggesting that these consults may have been obtained in the end-of-life setting. The increased likelihood of death in these patients is likely reflective of poor functional status, extensive disease burden and/or poor prognosis, leading to an accelerated PC referral.

Researchers have analyzed the different components of a PC visit to identify the mechanisms by which these referrals provide the benefits described above. What a PC provider chooses to focus on in each visit has an impact upon distinct patient-centered outcomes. For example, an ambulatory PC consultation can assist in symptom management, prognostic understanding, provide additional support from a psychosocial perspective, and elucidate 
a patient's goals for their end-of-life care. One analysis found that patients who had a higher proportion of visits addressing coping of symptoms reported improved QoL and depression scores, while patients who had more visits addressing treatment decisions were less likely to receive aggressive end-of-life care, and patients who had more visits discussing advance care planning were more likely to enroll in hospice [11]. Early PC referral in patients with advanced lung cancer has also been demonstrated to increase understanding of prognosis [12]. With this evidence supporting the benefits of early PC involvement, there has been a dramatic upswing in the number of patients referred to PC within 1 year of diagnosis of metastatic lung cancer [13]. However, even though the percentage of patients referred has increased nearly tenfold; from 3\% to over 30\% from 2001 to 2013, the majority of patients still did not receive PC referral, and only a quarter of them received outpatient PC services [13]. Thus, despite the known benefits, the majority of patients with advanced lung cancer do not interact routinely with a PC provider.

\section{PC needs in patients with advanced lung cancer}

\section{Symptom burden}

Patients diagnosed with lung cancer, particularly in advanced stages, report many physical and emotional symptoms that impair their QoL [14]. Common symptoms reported in lung cancer include pain, dyspnea, cough, fatigue, depression and anxiety. Even in patients who survive more than a year after diagnosis, more than half will report being afflicted with many of these symptoms [15]. Despite the development of new therapies, surveys done of patients with advanced lung cancer continue to demonstrate a high symptom burden [16]. At diagnosis, patients often report high levels of distress related to their emotional and functional well-being [17], and patients with lung cancer have been found to have higher levels of psychological distress compared with other cancers [18]. In turn, higher levels of emotional and psychological distress are associated with an increased symptom burden [19]. Unsurprisingly, patients closer to death report increasing burden and intensity of these symptoms [15]. Early PC focused on symptom management including psychosocial care can mitigate symptoms and prevent further exacerbation of symptoms already present. As part of their specialized training, PC providers are uniquely equipped to manage cancer-associated pain through a combination of multiple modalities, including the judicious prescription of opioid and nonopioid medications. In addition, they are trained to recognize and intervene on symptoms of dyspnea, gastrointestinal issues and insomnia, among others. As the purpose of the review is to offer a broader overview of the historical, current and future role of PC in lung cancer patients, the specifics of managing these symptoms can be reviewed in greater detail in previously published studies [20]. In sum, the goal of PC is to improve QoL due to both disease and toxicities from therapy.

\section{Intervention as PC}

In the setting of advanced lung cancer, cancer-directed treatment itself can serve to palliate symptoms. This was demonstrated as early as the 1990s, where two studies evaluating different chemotherapy regimens and their ability to reduce symptoms in patients with advanced-stage lung cancer documented an appreciable reduction in cough, pain and dyspnea in comparison with no treatment at all [21,22]. These studies helped to prove the concept that treatment to prolong life, if not to cure disease, may have the ability to palliate symptoms in the appropriate clinical context. However, we are also acutely aware that cytotoxic chemotherapies often lead to inferior outcomes and likely poor QoL in patients with poor performance status and therefore poor performance status generally precludes patients from receiving systemic chemotherapy [23]. The landscape of systemic therapies has now expanded to include immunotherapy and targeted therapies. Targeted therapies in select lung cancer populations harboring mutations in EGFR, ALK, ROS, BRAF and potentially newer targets such as NTRK, can also demonstrably improve $\mathrm{QoL}$, and do so in a superior fashion compared with standard chemotherapy regimens [24,25]. Because these therapies are generally associated with a milder side effect profile, these treatments are now often being offered to elderly or frailer patients, regardless of functional status, so long as side effects remain tolerable. Immunotherapies are currently still under study but are increasingly being used in patients with a worse performance study than those eligible for the primary clinical trials, with promising results [26]. Because of this, we suspect that immunotherapy will be used hand-in-hand with PC, in patients who would otherwise not be candidates for any systemic therapies.

Palliative radiation represents another modality of treatment often used to relieve symptoms without the intent to cure the overall disease. When a particularly troubling symptom is due to locoregional recurrence, but the patient otherwise is not a candidate for curative treatment, radiation can be used to good effect in up to two-thirds of patients [27]. Symptoms due to locoregional disease or spread that may be appropriate targets for radiation include cough due to airway compression, or pain due to painful osseous metastasis, among others [28]. 
Other minimally invasive procedures can be used to manage malignant airway obstruction such as through endobronchial stenting or malignant pleural effusions, through thoracentesis or placement of a pleural catheter [29]. With the increasing number of less invasive options available to help manage complications of advanced lung cancer, palliative surgery has become less common and is generally only used as a last resort. For example, pleurodesis historically has been offered for malignant pleural effusions, but in comparison with the placement of an indwelling pleural catheter, may lead to more days of hospitalization [30,31]. In special circumstances, such as that associated with malignant cord compression where patients are previously ambulatory, it is suggested that urgent surgical resection can lead to the recovery of function and the improvement of QoL, although the rate of associated surgical complications is also quite high [32]. Pericardial windows may also be used for malignant pericardial effusions.

All these modalities of therapies can be and likely should be achieved in conjunction with the application of PC.

\section{Aggressive end-of-life care}

Multiple recent studies have noted a trend in increasing use of aggressive inpatient end-of-life care, including intensive care unit stays and use of anticancer therapies near the end-of-life in lung cancer patients [33-36]. Aggressive cancer therapy in the last month of life is associated with increased likelihood of dying in the hospital. This trend is alarming both due to survey data that confirm patients wish to die at home, and quality-of-care metrics that encourage decreased aggressive end-of-life care with a focus on comfort and care at home [37-39]. A study examining trends of ICU hospitalizations for patients with metastatic lung cancer found that between 1998 and 2014, the percentage of patients admitted to the intensive care unit more than doubled, from 13.3 to $27.9 \%$ [33]. Although inpatient PC referrals also increased and were associated with reductions in aggressive end-of-life care as well as reductions cost, these referrals did not offset the increased costs to the healthcare system associated with intensive care stays. Several studies have demonstrated that early PC referral significantly decreases the use of aggressive end-of-life care $[2,40]$. Incorporating PC for these patients may reverse the current trend toward increasing aggressive end-of-life care.

\section{Understanding criteria for referral to $P C$}

In this section, we will discuss current existing guidelines for PC referral, and how to refine these criteria to everyday clinical practice. American Society of Clinical Oncology (ASCO) guidelines currently recommend that patients with advanced cancer as well as their caregivers should receive dedicated PC services within 8 weeks of diagnosis while receiving treatment [1]. However, this number of referrals would rapidly overwhelm the currently existing subspecialty PC taskforce, and would not account for patients who live in areas where subspecialty PC may not be readily available. In addition, there exists a global shortage of PC providers both within and outside of the USA.

Due to the tension between patients who are eligible for referral, and the number of patients who can be seen, there have been a variety of attempts to identify appropriate referral criteria in patients with cancer $[41,42]$. Hui et al. performed a Delphi study which relied on a panel of 60 international experts to reach a consensus on major and minor criteria for guiding outpatient PC referrals [43]. In this study, 11 major criteria were identified: the presence of severe physical or emotional symptoms, if a patient requested for hastened death, spiritual or existential crisis, assistance with decision making or advance care planning, certain morbid complications such as spinal cord compression, brain or leptomeningeal metastases, or delirium, if a patient requested referral, within 3 months of diagnosis of a cancer with projected survival of 1 year or less, and progression after second-line therapy [43]. In addition, they also agreed upon 36 minor criteria, defined as criteria where less than $70 \%$ of experts reached a consensus, further highlighting the challenges faced in generating these criteria.

A recent Canadian observational study attempted to identify the feasibility of applying these criteria to their population of lung cancer patients [44]. In their study, they limited the previously defined Delphi criteria to six only: within 3 months of a cancer diagnosis with projected survival less than a year, progression after second-line therapy, brain or leptomeningeal metastases, cord compression/cauda equina, and severe physical or emotional symptoms. Of the 28,164 patients who met criteria for PC referral by these metrics, $82.4 \%$ received PC referral, at a median time of 56 days after eligibility for PC referral. As a feasibility study, this is suggestive that this more limited set of guidelines can be implemented at a nationwide level.

While there is a clear distinction in the illness trajectory in certain metastatic solid cancers compared with others, there still exist more prognostic similarities than differences. Our argument is that advanced lung cancer does not require a separate set of guidelines for PC. Metastatic lung cancer remains a terminal diagnosis with a projected life expectancy measured in months, although prognosis has improved significantly for certain subsets of patients. 


\begin{tabular}{|c|c|c|}
\hline Delphi criteria (major only) & Modified Delphi criteria & Basic criteria \\
\hline $\begin{array}{ll}\text { - } & \text { Severe physical symptoms } \\
\text { - } & \text { Severe emotional symptoms } \\
& \text { Patient request for hastened } \\
\text { - } & \text { death } \\
\text { - } & \text { Asiritual or existential crisis } \\
& \text { making or advance care } \\
\text { - } & \text { Spanning } \\
\text { - } & \text { Brain or leptomeningeal } \\
\text { - } & \text { metastases } \\
\text { - } & \text { At pelium } \\
\text { - Within } 3 \text { months of diagnosis } \\
\text { of cancer with projected } \\
\text { survival of } 12 \text { months or less } \\
\text { Progression after second-line } \\
\text { therapy }\end{array}$ & $\begin{array}{ll} & \text { Severe physical symptoms } \\
\text { - } & \text { Severe emotional symptoms } \\
\text { - } & \text { Brain or leptomeningeal } \\
\text { - } & \text { Spiastases } \\
\text { - } & \text { Within } 3 \text { months of diagnosis } \\
& \text { of cancer with projected } \\
\text { survival of } 12 \text { months or less } \\
\text { Progression after second-line } \\
\text { therapy }\end{array}$ & $\begin{array}{l}\text { - If provider would not be } \\
\text { surprised if patient were to die } \\
\text { within a year } \\
\text { Poor functional or } \\
\text { performance status } \\
\text { - Severe emotional or physical } \\
\text { symptoms }\end{array}$ \\
\hline
\end{tabular}

Figure 1. Different sets of criteria for palliative care referral.

For example, some patients with EGFR-mutant lung cancers may experience impeccable disease control on the newest targeted therapy for a year and a half [45], and other patients may continue on indefinite immunotherapy on timelines that, 5 years ago, would have been unthinkable. However, even in these patients, after progression with first-line therapy, the efficacy of available second-line therapies declines significantly. Therefore, in patients whose available therapies are associated with survival of a year or less, a referral to PC would be reasonable.

For a more holistic understanding of which patients may be appropriate for PC, we would recommend referral of patients with advanced lung cancer to PC who:

- The provider would not be surprised if they were to die within a year;

- Have poor functional or performance status (e.g., Eastern Cooperative Oncology Group [ECOG] status III or above);

- Are suffering from severe physical or emotional symptoms.

Figure 1 represents a summary of these different referral guidelines.. It is likely unsustainable to refer every patient with advanced lung cancer to PC upon diagnosis. For some, such as the patient who has minimal symptoms and an available therapy to which they are expected to respond for many months to years, a PC referral may offer limited benefit and should be reserved for when symptoms worsen, or progression of disease occurs. For the time being, we recommend that referrals be made based on the state of available therapies for each patient's lung cancer and the patient's functional status and distress burden.

\section{Models of care delivery in PC}

Several different conceptual models for the integration and delivery of PC exist. Hui et al. broke down the provision of PC into three different models [46]:

- The onco-centric or solo practice model, wherein the oncologist handles all supportive symptoms in addition to oncologic care;

- The congress model, wherein the oncologist refers patients to specialists that focus on each symptom (e.g., for pain, a referral to a pain specialist and for depression, a referral to a psychiatrist);

- The integrated care model, in which the oncologist makes an early referral to specialist PC, and supportive care is provided by both the oncology and PC teams in tandem. 
The integrated care model likely offers more support to oncologic providers who already face the multiple tasks of providing optimal cancer-directed care than the solo practice model, and more unity of care for each patient than the congress model, which is reliant upon multiple subspecialty evaluations and recommendations.

In spite of the benefits of the integrated care model, there simply are not enough PC physicians or specialists for every patient who has advanced cancer. This means that primary PC remains an important avenue of providing PC. However, providing good primary PC is no easy task. Primary PC, if delivered by an oncologist, must contend with the multiple other clinical issues that demand an oncologist's attention. Because of this, symptoms or signs of distress may be overlooked or inadequately treated. Moreover, while there is increased emphasis on incorporating dedicated education on PC within oncology training, the level of comfort and knowledge at providing PC varies widely among non-PC trained physicians. We know that PC is effective in the studies discussed above because a structured intervention is prescribed and dedicated time is provided for this structured intervention. Primary PC is often unsuccessful precisely because these necessary criteria are not met. Sometimes, even when access to PC is not an issue, personal opinion and misconceptions regarding the role of $\mathrm{PC}$ from both the provider and the patient can lead to reduced appropriate referrals to PC [47]. For both models of delivery, there is still much to strive to improve. On the one hand, increasing our dedicated PC workforce is an endeavor that will require years, if not decades, of investment from governments and healthcare systems. This means that in the interim, coming up with new and innovative ways of improving primary PC and its intersection with specialist PC will be essential.

\section{Distress screening \& patient-reported outcomes: the missing links between integrating oncologic \& PC?}

Methods to capture patient symptoms in real-time and act upon them provide an opportunity to bridge the gap between oncologic and PC. Since 1997, the National Comprehensive Cancer Network (NCCN) has mandated distress screening as a part of cancer care [48]. The NCCN defines distress as "a multifactorial unpleasant experience of a psychological (i.e., cognitive, behavioral and emotional), social, spiritual and/or physical nature that may interfere with the ability to cope effectively with cancer, its physical symptoms and its treatment. It extends along a continuum, ranging from common, normal feelings of vulnerability, sadness and fears to problems that can be disabling, such as depression, anxiety, panic, social isolation, and existential and spiritual crisis [49]." With this definition, the NCCN has proposed a conceptual framework for psychosocial health as an integral part of the care of cancer patients. Since then, additional organizations have come forward to mandate distress screening as well, including the American College of Surgeons Commission on Cancer, the Institute of Medicine and ASCO [50-52].

Patient-reported outcomes (PROs) have become an increasingly important outcome of interest in both clinical trials and in general clinical practice [53]. PROs provide information on the physical, mental and social health of a patient as directly reported by the patient. Prior studies have demonstrated that clinician-reported outcomes are unable to fully capture the symptoms that patients report in clinical trial settings [30,54,55]. In 2017, Basch et al. found that integrating PROs into the routine care of patients with advanced cancer led to a statistically significant improvement in overall survival in a single tertiary care cancer center [56]. In patients randomized to PRO integration, not only did they have a longer overall survival, but were also able to tolerate continuation of chemotherapy for longer, suggesting that effective use of PROs may have allowed providers to manage treatment-related symptoms in a superior fashion.

A number of systematic reviews have reported that PROs appeared to be effective in improving patient-provider communication as well as patient satisfaction, but were not clearly impactful on patient outcomes [57,58]. More recently, another trial reported their final survival outcomes in patients with stage IIA-IV lung cancer who received either web-based monitoring of PROs or routine care with scheduled imaging, with again a significant increase in overall survival in the experimental arm [59]. If used correctly, PROs have the potential to improve both patient symptoms and overall survival outcomes. Although the body of literature to support regular use of PROs is still actively growing, based on the evidence thus far, institutions are increasingly adopting the use of PROs in routine clinical care.

PROs are also strongly prognostic for overall survival and other survival metrics [60,61]. If PROs can be used not only to monitor increasing symptom burden but can also be used to guide appropriate timing for referrals and adjustments in management, then perhaps the natural course of a patient's disease can be changed. However, this is dependent upon a reliable measurement tool. PRO measures are the tools that can be used to capture PROs. Multiple validated PRO measures exist that focus on patient symptoms and QoL, many of which focus specifically on lung cancer. Moreover, using electronic technology to record these PROs has been proven to be feasible, accurate 


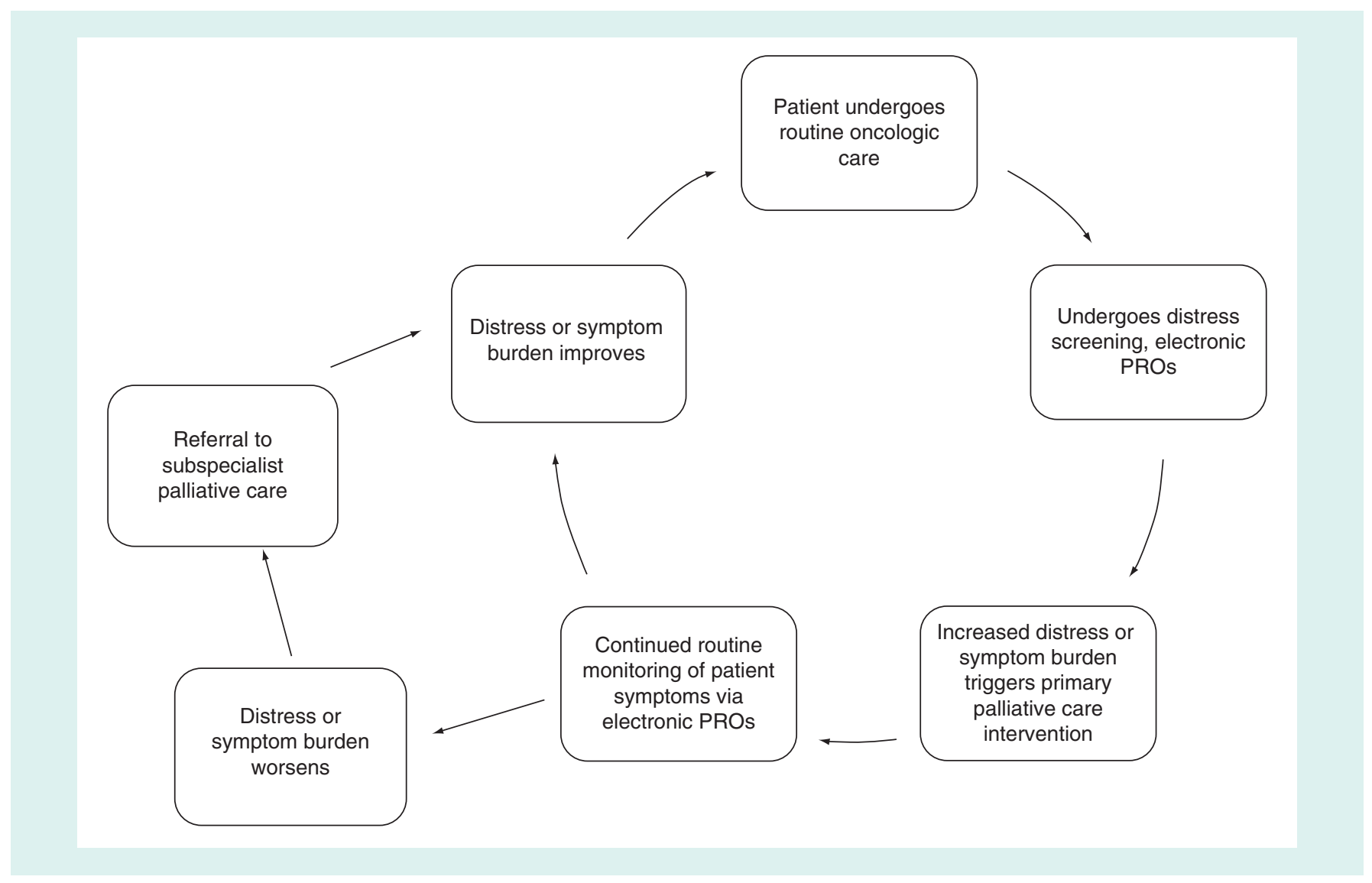

Figure 2. Conceptual model of incorporating electronic patient-reported outcomes and distress screening of cancer patients into facilitating primary palliative care interventions and specialist palliative care referral.

PRO: Patient-reported outcomes.

and acceptable for patients [62,63], and can increase accessibility to PROs to a wider population of patients via the use of electronic PROs (ePROs). However, while the technology and the evidence exists for the use of ePROs, the infrastructure from a health policy and reimbursement standpoint is still lacking [64].

\section{Conclusion}

Lung cancer remains a highly prevalent, highly symptomatic disease both globally and nationwide. In spite of advances in therapy, we still lag behind in managing the symptoms associated with both the disease and the treatment. PC is a rapidly growing field that focuses on a multidisciplinary approach of treating patients with serious illness, as well as their caregivers. In patients with advanced lung cancer, PC has been demonstrated to improve quality of life outcomes as well as potentially survival. However, there still exist many unmet needs in patients with advanced lung cancer, and currently existing models of integrating oncologic and PC have not been able to fully bridge that gap. Increasing the use of PROs may facilitate this integration, thus improving cancer care and symptom management of lung cancer patients, as well as cancer patients as a whole.

\section{Future perspective}

Data obtained from the now mandated distress surveys and a more widespread use of ePROs could be used to trigger additional screening and telephone follow-ups for patients reporting increasing or severe symptoms. This could enhance the delivery of primary PC. For example, ePROs can become an effective method of managing symptoms from afar, as seen in the Symptom Care at Home intervention where patients receiving chemotherapy called an automated monitoring system daily with a protocol-driven nurse practitioner telephone follow-up. This intervention led to a 57\% reduction in reported symptom burden compared with the usual care arm $[65,66]$. Our future model of PROs and PC utilize PROs to do the initial triage. Patients who do not experience a symptom 
burden reduction with this primary PC intervention may then be identified as patients who should be escalated to a specialist PC intervention. Of note, with our recent learnings from the COVID-19 pandemic, we also see a role for telemedicine as a means to improve access and if a remote option is available, then this may represent an opportunity to expand access to PC. Use of telemedicine in PC has shown improvements in QoL and patient satisfaction [67]. In this model of care, an oncologic practice thus follows best-care practices of distress screening, incorporates ePROs which enhances patient reporting of symptoms, manages symptoms in a timely manner and screens for patients who would most benefit from specialist PC services (Figure 2). This model makes efficient use of existing resources without sacrificing attention to patient symptoms. Moreover, as a pandemic has swept the world, the provision of virtual care has become a daily necessity for many healthcare practices. As healthcare practices become more accustomed to managing patients from afar, we envision a future in which PROs through surveys and distress screenings are naturally incorporated into the routine care of patients, becoming a pulse by which we can monitor overall well-being and invite more intensive primary and secondary PC intervention when it appears needed.

\section{Executive summary}

Palliative care: definition

- The WHO defines palliative care (PC) as the care that focuses on improving quality of life for patients and families with serious illness by early and holistic understanding of physical, psychosocial and emotional problems.

Evolution of PC in lung cancer

- Early incorporation of PC has been proven to improve quality of life in patients with advanced lung cancer based on multiple high-quality randomized controlled trials.

- Current data also suggest that patients may experience benefits in overall survival.

PC needs in patients with advanced lung cancer

- Patients with lung cancer have a high symptom burden in spite of advancements in treatment.

- Patients with lung cancer are also demonstrating a trend toward increasing aggressive end-of-life care, a measurement of poor quality-of-care.

Understanding criteria for referral to PC

- Multiple sets of criteria have been formulated for referral to PC for lung cancer patients, but ultimately still depends on clinician judgment of each individual patient's overall prognosis including available treatment options, functional status and symptoms.

Models of care delivery in PC

- PC can be delivered using an oncocentric model, congress model or an integrated PC and oncologic care model.

- In the current existing infrastructure, improving PC delivery in rural or community settings will likely rely upon developing structured methods of improving primary PC.

Future perspective

- Mandated distress surveys and electronic patient-reported outcomes represent the future of real-time symptom monitoring for cancer patients.

- Using these tools also represent an opportunity to fine-tune the delivery of primary PC and identify patients who may most benefit from referral to specialist primary care.

Financial \& competing interests disclosure

The authors have no relevant affiliations or financial involvement with any organization or entity with a financial interest in or financial conflict with the subject matter or materials discussed in the manuscript. This includes employment, consultancies, honoraria, stock ownership or options, expert testimony, grants or patents received or pending, or royalties.

No writing assistance was utilized in the production of this manuscript.

Open access

This work is licensed under the Attribution-NonCommercial-NoDerivatives 4.0 Unported License. To view a copy of this license, visit http://creativecommons.org/licenses/by-nc-nd/4.0/

\section{References}

Papers of special note have been highlighted as: • of interest; $\bullet \bullet$ of considerable interest

1. Ferrell BR, Temel JS, Temin S et al. Integration of palliative care into standard oncology care: American Society of Clinical Oncology clinical practice guideline update. J. Clin. Oncol. 35(1), 96-112 (2017).

2. Temel JS, Greer JA, Muzikansky A et al. Early palliative care for patients with metastatic non-small-cell lung cancer. N. Engl. J. Med. 363(8), 733-742 (2010). 
-. This seminal trial demonstrates clear benefits in quality-of-life measures and improved survival with early palliative care (PC) for advanced lung cancer patients.

3. Dionne-Odom JN, Azuero A, Lyons KD et al. Benefits of early versus delayed palliative care to informal family caregivers of patients with advanced cancer: outcomes from the ENABLE III randomized controlled trial. J. Clin. Oncol. 33(13), 1446 (2015).

4. National Cancer InstituteNational Cancer Institute. Surveillance E, Program ER. Cancer stat facts: lung and bronchus cancer. (2018). https://seer.cancer.gov/statfacts/html/lungb.html

5. Mendoza TR, Kehl KL, Bamidele $\mathrm{O}$ et al. Assessment of baseline symptom burden in treatment-naïve patients with lung cancer: an observational study. Support. Care Cancer 27(9), 3439-3447 (2019).

6. Sepúlveda C, Marlin A, Yoshida T, Ullrich A. Palliative care: the World Health Organization's global perspective. J. Pain Symptom Manage. 24(2), 91-96 (2002).

7. Bakitas M, Lyons KD, Hegel MT et al. Effects of a palliative care intervention on clinical outcomes in patients with advanced cancer: the project ENABLE II randomized controlled trial. JAMA 302(7), 741-749 (2009).

8. Bakitas MA, Tosteson TD, Li Z et al. Early versus delayed initiation of concurrent palliative oncology care: patient outcomes in the ENABLE III randomized controlled trial. J. Clin. Oncol. 33(13), 1438 (2015).

9. Zimmermann C, Swami N, Krzyzanowska M et al. Early palliative care for patients with advanced cancer: a cluster-randomised controlled trial. Lancet 383(9930), 1721-1730 (2014).

10. Sullivan DR, Chan B, Lapidus JA et al. Association of early palliative care use with survival and place of death among patients with advanced lung cancer receiving care in the Veterans Health Administration. JAMA Oncol. 5(12), 1702-1709 (2019).

11. Hoerger M, Greer JA, Jackson VA et al. Defining the elements of early palliative care that are associated with patient-reported outcomes and the delivery of end-of-life care. J. Clin. Oncol. 36(11), 1096 (2018).

- This trial concretely linked target interventions by PC with specific changes in patient outcomes.

12. Temel JS, Greer JA, Admane S et al. Longitudinal perceptions of prognosis and goals of therapy in patients with metastatic non-small-cell lung cancer: results of a randomized study of early palliative care. J. Clin. Oncol. 29(17), 2319-2326 (2011).

13. Huo J, Hong YR, Turner K, Bian J, Grewal R, Wilkie DJ. Utilization pattern and service settings of palliative care for patients with metastatic non-small-cell lung cancer. Cancer 125(24), 4481-4489 (2019).

14. Cooley ME. Symptoms in adults with lung cancer: a systematic research review. J. Pain Symptom Manage. 19(2), 137-153 (2000).

15. Tishelman C, Petersson L-M, Degner LF, Sprangers MA. Symptom prevalence, intensity, and distress in patients with inoperable lung cancer in relation to time of death. J. Clin. Oncol. 25(34), 5381-5389 (2007).

16. Sung MR, Patel MV, Djalalov $S$ et al. Evolution of symptom burden of advanced lung cancer over a decade. Clin. Lung Cancer 18(3), 274-280 (2017).

17. Kuon J, Vogt J, Mehnert A et al. Symptoms and needs of patients with advanced lung cancer: early prevalence assessment. Oncol. Res. Treat. 42(12), 650-659 (2019).

18. Zabora J, Brintzenhofeszoc K, Curbow B, Hooker C, Piantadosi S. The prevalence of psychological distress by cancer site. Psychooncology 10(1), 19-28 (2001).

19. Morrison EJ, Novotny PJ, Sloan JA et al. Emotional problems, quality of life, and symptom burden in patients with lung cancer. Clin. Lung Cancer 18(5), 497-503 (2017).

20. Ferrell B, Koczywas M, Grannis F, Harrington A. Palliative care in lung cancer. Surgical Clinics 91(2), $403-417$ (2011).

21. Ellis P, Smith I, Hardy J et al. Symptom relief with MVP (mitomycin C, vinblastine and cisplatin) chemotherapy in advanced non-small-cell lung cancer. Br. J. Cancer 71(2), 366-370 (1995).

22. Cullen M, Billingham L, Woodroffe $\mathrm{C}$ et al. Mitomycin, ifosfamide, and cisplatin in unresectable non-small-cell lung cancer: effects on survival and quality of life. J. Clin. Oncol. 17(10), 3188-3194 (1999).

23. Sweeney CJ, Zhu J, Sandler AB et al. Outcome of patients with a performance status of 2 in eastern cooperative oncology group study E1594: a Phase III trial in patients with metastatic nonsmall cell lung carcinoma. Cancer 92(10), 2639-2647 (2001).

24. Thongprasert S, Duffield E, Saijo N et al. Health-related quality-of-life in a randomized Phase III first-line study of gefitinib versus carboplatin/paclitaxel in clinically selected patients from Asia with advanced NSCLC (IPASS). J. Thorac. Oncol. 6(11), 1872-1880 (2011).

25. Lee CK, Novello S, Rydén A et al. Patient-reported symptoms and impact of treatment with osimertinib versus chemotherapy in advanced non-small-cell lung cancer: the AURA3 trial. J Clin Oncol. 36(18), 1853-1860 (2018).

26. Brustugun OT, Sprauten M, Helland Å. Real-world data on nivolumab treatment of non-small-cell lung cancer. Acta Oncol. 56(3), 438-440 (2017).

27. Budach W, Belka C. Palliative percutaneous radiotherapy in non-small-cell lung cancer. Lung Cancer 45, S239-S245 (2004).

28. Fairchild A, Harris K, Barnes E et al. Palliative thoracic radiotherapy for lung cancer: a systematic review. J. Clin. Oncol. 26(24), 4001-4011 (2008). 
29. Mallow C, Hayes M, Semaan R et al. Minimally invasive palliative interventions in advanced lung cancer. Expert Rev. Respir. Med. 12(7), 605-614 (2018).

30. Atkinson TM, Li Y, Coffey CW et al. Reliability of adverse symptom event reporting by clinicians. Qual. Life Res. 21(7), 1159-1164 (2012).

31. Iyer NP, Reddy CB, Wahidi MM et al. Indwelling pleural catheter versus pleurodesis for malignant pleural effusions. A systematic review and meta-analysis. Ann. Am. Thorac. Soc. 16(1), 124-131 (2019).

32. Park SJ, Lee CS, Chung SS. Surgical results of metastatic spinal cord compression (MSCC) from non-small cell lung cancer (NSCLC): analysis of functional outcome, survival time, and complication. Spine J. 16(3), 322-328 (2016).

33. Mrad C, Abougergi MS, Daly B. One step forward, two steps back: trends in aggressive inpatient care at the end of life for patients with stage IV lung cancer. J. Oncol. Pract. 14(12), e746-e757 (2018).

34. Bylicki O, Didier M, Riviere F, Margery J, Grassin F, Chouaid C. Lung cancer and end-of-life care: a systematic review and thematic synthesis of aggressive inpatient care. BMJ Support Palliat. Care 9(4), 413-424 (2019).

35. Presley CJ, Han L, O'Leary JR et al. Concurrent hospice care and cancer-directed treatment for advanced lung cancer and receipt of aggressive care at the end of life in the Veteran's Health Administration. J. Palliat. Med. doi.org/10.1089/jpm.2019.0485 (2020) (Epub ahead of print).

36. Smith CE, Kamal AH, Kluger M, Coke P, Kelley MJ. National trends in end-of-life care for veterans with advanced cancer in the Veterans Health Administration: 2009 to 2016. J. Oncol. Pract. 15(6), e568-e575 (2019).

37. Mieras A, Pasman HRW, Onwuteaka-Philipsen BD et al. Is in-hospital mortality higher in patients with metastatic lung cancer who received treatment in the last month of life? A retrospective cohort study. J. Pain Symptom Manage. 58(5), 805-811 (2019).

38. Wilson DM, Cohen J, Deliens L, Hewitt JA, Houttekier D. The preferred place of last days: results of a representative population-based public survey. J. Palliat. Med. 16(5), 502-508 (2013).

39. Earle CC, Park ER, Lai B, Weeks JC, Ayanian JZ, Block S. Identifying potential indicators of the quality of end-of-life cancer care from administrative data. J. Clin. Oncol. 21(6), 1133-1138 (2003).

40. Amano K, Morita T, Tatara R, Katayama H, Uno T, Takagi I. Association between early palliative care referrals, inpatient hospice utilization, and aggressiveness of care at the end of life. J. Palliat. Med. 18(3), 270-273 (2015).

41. Hui D, Meng YC, Bruera S et al. Referral criteria for outpatient palliative cancer care: a systematic review. Oncologist 21(7), 895-901 (2016).

42. Hui D, Titus A, Curtis T et al. Implementation of the Edmonton Symptom Assessment System for symptom distress screening at a community cancer center: a pilot program. Oncologist 22(8), 995-1001 (2017).

43. Hui D, Mori M, Watanabe SM et al. Referral criteria for outpatient specialty palliative cancer care: an international consensus. Lancet Oncol. 17(12), e552-e559 (2016).

- An international panel details the clinical features that should inspire outpatient PC referral in this report.

44. Iqbal J, Sutradhar $\mathrm{R}$, Zhao $\mathrm{H}$ et al. Operationalizing outpatient palliative care referral criteria in lung cancer patients: a population-based cohort study using health administrative data. J. Palliat. Med. 23(5), 670-677 (2020).

45. Soria J-C, Ohe Y, Vansteenkiste J et al. Osimertinib in untreated EGFR-mutated advanced non-small-cell lung cancer. N. Engl. J. Med. 378(2), 113-125 (2018).

46. Hui D, Bruera E. Models of integration of oncology and palliative care. Ann. Palliat. Med. 4(3), 89-98 (2015).

47. Wentlandt K, Krzyzanowska MK, Swami N, Rodin GM, Le LW, Zimmermann C. Referral practices of oncologists to specialized palliative care. J. Clin. Oncol. 30(35), 4380-4386 (2012).

48. Holland JC, Andersen B, Breitbart WS et al. Distress management. J. Natl Compr. Canc. Netw. 11(2), 190-209 (2013).

49. Network NCC. NCCN clinical practice guidelines in oncology: distress management. (2010). http://oralcancerfoundation.org/treatment/pdf/distress

50. Cancer ACOSCO. Cancer Program Standards 2012 Version 1.1: Ensuring Patient-Centered Care. (2012). http://www.facs.org/ /media/files/quality\%20programs/cancer/coc/programstandards2012.ash

51. Page AE, Adler NE. Cancer Care for the Whole Patient: Meeting Psychosocial Health Needs. National Academies Press, Washington DC, USA (2008).

52. Smith SK, Loscalzo M, Mayer C, Rosenstein DL. Best practices in oncology distress management: beyond the screen. Am. Soc. Clin. Oncol. Educ. Book 38, 813-821 (2018).

53. Strong LE. The past, present, and future of patient-reported outcomes in oncology. Am. Soc. Clin. Oncol. Educ. Book 35(1), e616-e620 (2015).

54. Quinten C, Maringwa J, Gotay CC et al. Patient self-reports of symptoms and clinician ratings as predictors of overall cancer survival. J. Natl Cancer Inst. 103(24), 1851-1858 (2011).

55. Fromme EK, Eilers KM, Mori M, Hsieh Y-C, Beer TM. How accurate is clinician reporting of chemotherapy adverse effects? A comparison with patient-reported symptoms from the Quality-of-Life questionnaire C30. J. Clin. Oncol. 22(17), 3485-3490 (2004). 
56. Basch E, Deal AM, Dueck AC et al. Overall survival results of a trial assessing patient-reported outcomes for symptom monitoring during routine cancer treatment. JAMA 318(2), 197-198 (2017).

- A seminal trial that demonstrates concrete improvement in patient outcomes including potential improvement of survival via monitoring of patient-reported outcomes.

57. Chen J, Ou L, Hollis SJ. A systematic review of the impact of routine collection of patient reported outcome measures on patients, providers and health organisations in an oncologic setting. BMC Health Serv. Res. 13(1), 211 (2013).

58. Kotronoulas G, Kearney N, Maguire R et al. What is the value of the routine use of patient-reported outcome measures toward improvement of patient outcomes, processes of care, and health service outcomes in cancer care? A systematic review of controlled trials. J. Clin. Oncol. 32(14), 1480-1510 (2014).

59. Denis F, Basch E, Septans A-L et al. Two-year survival comparing web-based symptom monitoring vs routine surveillance following treatment for lung cancer. JAMA 321(3), 306-307 (2019).

60. Kerrigan K, Patel SB, Haaland B et al. Prognostic significance of patient-reported outcomes in cancer. JCO Oncol. Pract. 16(4), e313-e323 (2020).

61. Suh S-Y, Leblanc TW, Shelby RA, Samsa GP, Abernethy AP. Longitudinal patient-reported performance status assessment in the cancer clinic is feasible and prognostic. J. Oncol. Pract. 7(6), 374-381 (2011).

62. Abernethy AP, Herndon JE, Wheeler JL et al. Improving health care efficiency and quality using tablet personal computers to collect research-quality, patient-reported data. Health Serv. Res. 43(6), 1975-1991 (2008).

63. Dupont A, Wheeler J, Herndon J et al. Use of tablet personal computers for sensitive patient-reported information. J. Support. Oncol. 7(3), 91-97 (2009).

64. Leblanc TW, Abernethy AP. Patient-reported outcomes in cancer care - hearing the patient voice at greater volume. Nat. Rev. Clin. Oncol. 14(12), 763-772 (2017).

65. Mooney KH, Beck SL, Wong B et al. Automated home monitoring and management of patient-reported symptoms during chemotherapy: results of the symptom care at home RCT. Cancer Med. 6(3), 537-546 (2017).

66. Worster B, Swartz K. Telemedicine and palliative care: an increasing role in supportive oncology. Curr. Oncol. Rep. 19(6), 37 (2017).

67. Hennemann-Krause L, Lopes AJ, Araújo JA, Petersen EM, Nunes RA. The assessment of telemedicine to support outpatient palliative care in advanced cancer. Palliat. Support. Care 13(4), 1025-1030 (2015). 